\title{
The Role of Empirical Research in Bioethics
}

\author{
Alexander A. Kon \\ University of California Davis
}

\section{Abstract}

There has long been tension between bioethicists whose work focuses on classical philosophical inquiry and those who perform empirical studies on bioethical issues. While many have argued that empirical research merely illuminates current practices and cannot inform normative ethics, others assert that research-based work has significant implications for refining our ethical norms. In this essay, I present a novel construct for classifying empirical research in bioethics into four hierarchical categories: Lay of the Land, Ideal Versus Reality, Improving Care, and Changing Ethical Norms. Through explaining these four categories and providing examples of publications in each stratum, I define how empirical research informs normative ethics. I conclude by demonstrating how philosophical inquiry and empirical research can work cooperatively to further normative ethics.

\section{Keywords}

bioethics; clinical; empirical research; ethical analysis; ethical theory; ethics; principle-based ethics

\begin{abstract}
Bioethics, like most aspects of healthcare, requires the attention of a broad range of professionals to advance and improve. Clearly, the work of normative ethics is evident when discussing any bioethical issue. We have come to accept many normative concepts and use them in our everyday interactions with patients. Indeed, in nearly every healthcare encounter, the practitioner's concepts of self-determination, fiduciary responsibilities, honesty, integrity, and other ethical principles influence how he or she interacts with patients, families, and other professionals. Much of the work in building our ethical framework has been through classical philosophical methods. The careful examination of concepts, with debate and scrutiny, has led to wide acceptance of many such principles in clinical practice. Some ask, however, what is the role of empirical ethics research in bedside care? That is: How can the 'is' inform the 'ought?' In this essay, I attempt to answer that question by describing four categories of empirical research in ethics. For each category I provide examples to illustrate and support my assertions.

The framework I present is applicable both to healthcare ethics as a whole as well as research within healthcare subsections. While communication across professions in healthcare unfortunately is often inadequate, the themes running through research on ethical aspects of care (e.g., how we can communicate with patients more effectively, how we can provide improved care for the suffering patient, how we can employ the interdisciplinary team to the greatest benefit of patients and families) are common to all. Further, although many professionals seem to have a tendency to focus on work done within their profession or by members of their own profession, empirical research in topics related to bioethics
\end{abstract}

Address correspondence to Alexander A. Kon, Associate Professor of Pediatrics and Bioethics, University of California Davis, 2516 Stockton Boulevard, Sacramento, CA 95817. aakon@ucdavis.edu. 
tends to have broad applicability. The nature of bioethics makes it an interprofessional pursuit, and similarly, the empirical findings of research have implications for many different professionals in healthcare. Further, the examples provided in this essay are merely that, examples. An exhaustive list would be impractical.

It is beyond the scope of this work to present in detail the various methodologies employed in empirical research in bioethics. In the recent book edited by Jacoby and Siminoff (2008) one can find excellent explanations of eight distinct methodologies, both qualitative and quantitative. The first three categories I present here encompass both quantitative and qualitative methodologies, and while works in the fourth category may build on studies employing any methodology, the essays in the fourth category themselves do not directly employ empirical techniques. Further, while empirical studies may be categorized as descriptive, explanatory, outcome research, or meta-analysis, such labels to not translate directly into the categorization that I propose here.

In general, empirical research informs bioethics at one of four levels. These levels each build upon the other, and appear to have a hierarchical order. The first level of inquiry, and perhaps the most common example of such research, is Lay of the Land research. The second level of study explores how well actual clinical practice matches our ethical ideals, or Ideal versus Reality studies. The third level moves one step further to address how we can bring clinical practice closer in line with ethical ideals, or Improving Care studies. Finally, the highest order of work generally brings together data from multiple empirical studies on a single topic and uses these data to inform, and potentially change, our ethical ideals: i.e., Changing Ethical Norms articles. Each of these levels is important and yields information useful to bedside clinicians.

\section{LAY OF THE LAND}

Lay of the Land studies seek to define current practices, opinions, beliefs, or other aspects that may be considered the status quo. Such studies may be descriptive or explanatory in nature, and may or may not be hypothesis-driven. Studies included in this category are those asking questions such as: "What do physicians think about $x$ ?" "How do nurses perceive $Y$ ?" and "What do patients want regarding $Z$ ?" Research in this category may utilize qualitative or quantitative methodology. This work can set the stage for further research and may help direct efforts in improving care (e.g., if one finds that patients tend to be more satisfied when cared for by clinicians of the same ethnic background, one may develop future projects to assess why patients feel this way or how one may improve patient satisfaction when 'matching' providers is not feasible or desirable). Further, this data may be of interest to patients when making decisions about their own medical care.

Examples of such work are studies examining the practices and composition of hospital ethics committees (Fox et al. 2007; McGee et al. 2001). While there are some recommendations regarding ethics committee procedures (Arnold and Youngner 1998), there are no standards per se. Studies such as these can inform committee chairs how other committees function, and may assist chairs in advocating for resources, and are therefore of great value to the ethics community.

Another example in this first category is the plethora of research regarding attitudes and preferences in end-of-life care employing both quantitative methods (DeKeyser Ganz and Musgrave 2006; Duke and Thompson 2007; Rurup et al. 2006; Sprung et al. 2007) as well as qualitative methods (Daaleman et al. 2008; Lee and Dupree 2008; Li and Ng 2008). At the heart of this research is the question: "What do patients, families, and healthcare providers want regarding end-of-life care?" Such data is imperative as we develop end-oflife care practices and policies. Further, such studies investigating attitudes from different 
perspectives (e.g., nurses, physicians, patients, and families) can lay the groundwork for future inquiry assessing projects designed to bring these perspectives in line with one another and in assessing the efficacy of clinical end-of-life care programs.

A third type of study in this first category includes studies that seek knowledge that might help people who need to make difficult choices. Studies assessing the quality of life of adults with spinal cord injury (Abrantes-Pais Fde et al. 2007) and the long-term quality of life of children with spinal cord injury (Anderson et al. 2006) may be of great interest to patients and families when they need to choose between withdrawal of life prolonging measures versus long-term ventilator and feeding tube dependency. When parents of a newborn with hypoplastic left heart syndrome need to choose between multiple surgeries with suboptimal outcomes versus allowing their child die a natural death, many would likely find it helpful to know what experts in the care of these infants predict they would do if their own child was born with this syndrome (Kon et al. 2003). Likewise, when designing educational programs, most educators would find it important to know what patients want from their care providers (Houle et al. 2007). These are only a few examples of work that assists patients, families, and providers in decision-making.

\section{IDEAL VERSUS REALITY}

The second level of research, Ideal Versus Reality, starts with a premise regarding ethical norms and then seeks to assess the extent to which actual clinical practice reflects this ideal. Such work is imperative if one wishes to effect change in the healthcare system. Even if everyone agrees on an ideal, few will work towards improving a system without data demonstrating that the current system fails to meet this ideal. Studies in this second level are generally hypothesis-driven, and the hypothesis is generally that current practice fails to meet ethical norms. Again, such an assessment may be best made using either quantitative or qualitative methodology depending on the question being asked.

Perhaps the most famous work of this type is the body of evidence demonstrating that racial and ethnic minority patients receive less aggressive and lower quality care (Fiscella et al. 2000). Indeed, there are now thousands of articles in peer-reviewed journals demonstrating disparities in nearly every aspect of healthcare. The ethical premise is that we as a society believe that the amount and type of healthcare a patient receives ought not to be influenced by his or her race or ethnicity. This equality of care is a well-accepted ethical norm in the United States (Satcher 1999). The goal of this research endeavor has been to demonstrate our failure to live up to this ideal, and to investigate the depth and breadth of the problem. Through this body of work, it is now accepted that we must improve access to healthcare for both lower income and minority status persons, and that healthcare professionals must work to diminish disparate care.

The research on disparities in healthcare raises another broad issue of what is meant by 'bioethics' empirical research. Much of the empirical work on disparities has been conducted by individuals who do not consider themselves bioethicists, who do not consider their research to be research in the field of bioethics, and who publish their work in journals that are not generally considered bioethics journals. This finding points to the broad nature of research that may influence bioethics and potentially may lead to changes in our ethical norms. Further, many who are considered leaders in bioethics do not consider themselves to be bioethicists per se, but rather clinicians or researchers whose work is related to bioethics. Regardless of who performs the research, in what field the researchers believe themselves to be, and in which journals the research is published, research that investigates issues that bioethicists believe fall under the bioethics umbrella may be viewed in the scheme I propose. Indeed, some of the studies that have had the greatest impact on bioethics have 
been conducted by individuals who do not consider themselves to be bioethicists. The value of empirical research in bioethics is based on the scientific methods and experimental rigor, not on the affiliation of the investigators, the title of the publication, or the journal in which the report appears.

Another topic that has been the subject of considerable investigation is that of informed consent for clinical research. Again, this work begins with a premise. It is accepted that when a person consents to participate in clinical research, that consent must be informed (Faden and Beauchamp 1986). It therefore follows that if a subject does not comprehend at least some basic aspects of the trial, his or her consent is invalid. Many researchers, therefore, have investigated subjects' comprehension of basic aspects of trials in which they are volunteers. Using both quantitative and qualitative methods, research has demonstrated that many research subjects fail to understand even the most basic aspects of clinical research including the purpose of the study, the voluntary nature of study participation, and the fact that the goal of the study is to increase generalizable knowledge and not necessarily to help individual study participants (Criscione et al. 2003; Joffe et al. 2001; Yuval et al. 2000). These data raise significant concerns because they show that many research subjects' consent is not informed consent.

A third example of this type of work is the body of evidence demonstrating that physicians often fail to disclose serious medical errors to patients. Given that society expects healthcare providers to disclose information that patients consider relevant, and given that most patients would consider a serious medical error to be an important piece of information and would want to know about that error, it follows that providers have an obligation to disclose such errors particularly when such errors can potentially effect medical care and outcomes. In the United States, although it did not ultimately become law, Senators Hillary Clinton and Barack Obama introduced the National Medical Error Disclosure and Compensation Act of 2005 that would have required healthcare providers to disclose errors to patients (Clinton and Obama 2005). Given this ethical standard, multiple studies have assessed the rate of error disclosure, and investigators have found that providers often fail to disclose errors to patients (Gallagher et al. 2006; Schoen et al. 2005). Qualitative studies have helped illuminate why healthcare providers often fail to disclose such errors (Luk et al. 2008), differences between provider and patient expectations in error disclosure (Fein et al. 2007), and other barriers to full disclosure. Together, this body of work has demonstrated that the reality of practice does not match our ideal.

These are only three examples from perhaps hundreds where empirical research has demonstrated gaps between our ethical ideals and the reality of healthcare. Through illuminating such dissonance, such studies can be catalysts of change. Many of the works cited above have been a call to arms leading to wide appreciation of ethical problems and public movements to bring our reality closer in line with our ideals.

\section{IMPROVING CARE}

The third level of empirical work seeks to find ways to solve problems identified by Ideal versus Reality research. Improving Care research projects build on previous work, designing and testing novel methods to help clinicians care for patients in ways more consistent with ethical norms. Broome (2008) presents a good overview of quantitative intervention research methodologies in the Jacoby and Siminoff text. Such work is critical if one hopes to effect real change.

As noted previously, a copious body of literature now exists cataloguing and measuring racial and ethnic disparities in nearly all aspects of healthcare. The natural next step is to design tools to diminish or eliminate such disparities, and then test the efficacy of these 
tools. While much work has focused on Ideal versus Reality level studies, relatively few publications report the effects of potential solutions. The work that has been done in this arena, however, shows promise and forms the basis for further inquiry (Abraham et al. 2007; Beach et al. 2007; Pilcher et al. 2008; Sequist et al. 2006). Because some projects that appear at first to be extremely promising fail to produce some of their anticipated results (Sequist et al. 2006), systematic examination of the utility of any intervention must be carried out and reported. Without this type of empirical work, we could potentially expend substantial resources on programs that fail to effect real change.

One well-known example of such work was the SUPPORT study (SUPPORT 1995). This project sought to demonstrate improved end-of-life care through the implementation of a standard approach to physician-patient communication utilizing specially trained nurses. The project required substantial effort, and the results demonstrated no significant improvement in patient care. Such research is crucial in determining both what methods may work, and what methods do not work, in improving the care provided to patients.

Further, while much research has focused on describing shortcomings in the informed consent process in clinical research (as described previously), fewer investigators have published studies evaluating techniques to improve subject comprehension. Some investigators, however, have developed tools to improve the consent process and have empirically evaluated the feasibility and efficacy of such tools (Campbell et al. 2004; Mittal et al. 2007; Tait et al. 2005). Again, such projects may employ qualitative, quantitative, or mixed methodologies. For example, our group is currently assessing the utility of a modified consent document and process employing both quantitative methods (to assess differences in comprehension of key study elements) as well as qualitative methods (to assess subtle differences in subjects' sense of preparedness for the study, their impression of whether the study was what they had expected, and general subject satisfaction with the consent process). Further, using qualitative methods investigators have demonstrated significant shortcomings in the use of any written consent documents (Dixon-Woods et al. 2007) raising the question of whether merely altering a form could ever sufficiently improve the consent process. The data presented in such work may be used by the research community at large to improve potential subjects' understanding of key aspects of study participation and thereby allow people to make more informed decisions regarding study enrollment.

Clearly Lay of the Land and Ideal versus Reality studies can be of great benefit in clinical care. Without Improving Care studies, however, we cannot ensure that our interventions will have the desired effect. Such studies are critical in improving care at the bedside, and therefore are of great importance and should be of interest to all healthcare professionals who provide direct patient care.

\section{CHANGING ETHICAL NORMS}

The fourth level, Changing Ethical Norms, builds on the work of the other three. These works generally are not individual empirical studies themselves, but rather bioethical analyses of multiple empirical publications. Through reviewing and analyzing empirical findings, authors recommend changes in our ethical norms. This is not to say that the norms merely reflect public opinion, rather that the empirical work informs our concept of appropriate actions. To be clear, work in this category is not analogous to meta-analysis research in which investigators pool data from multiple previous empirical projects. Rather, Changing Ethical Norms publications use the data obtained in previous projects to form the basis of a bioethical argument to change an ethical norm. Such work often is not limited to a single publication, and multiple publications may combine to gradually shift norms in practice. 
Perhaps the most recognized example of the impact empirical work can have on shaping ethical norms is the metamorphosis of our concept of medical decision-making. The history of the rise of informed consent is both long and complex, and a detailed description of it is beyond the scope of this essay. Faden and Beauchamp (1986), Katz (1984), and others have described the rise of patient autonomy in medical decision-making, and this long road was paved with philosophical inquiry, judicial review, and legislative action (e.g., the Patient Self-Determination Act). Autonomy in decision-making indeed has become so well accepted that many practitioners have abdicated all responsibility for decision-making, placing the burden squarely on the shoulders of patients. Indeed, some have argued that we are now in the predicament where patients are often "abandoned to their own autonomy" (Loewy 1998, 324). The shift away from paternalistic decision-making to autonomous decision-making in healthcare was not driven by empirical work, rather it was steered by the awareness that people have a right to make important medical decisions.

What we have witnessed in recent years, however, is a series of empirical projects demonstrating wide variability in the patient and family preferences regarding the decisionmaking processes (Azoulay et al. 2004; Heyland et al. 2003b; Johnson et al. 2000; Mazur et al. 2005; Salkeld et al. 2004; Shields et al. 2004). It took years to move from the paternalistic model to the autonomy model of decision-making in the United States, however these data suggest that we have moved too far. In 2004, a coalition of international societies devoted to the care of critically ill and dying patients produced a consensus statement supporting a shared decision-making model (Carlet et al. 2004; Thompson et al. 2004). This move away from strict autonomy to a more middle ground represents a sea change in the United States, brought upon by empirical studies. This is not to say that the empirical work in isolation is the catalyst for change, rather, this work brings to light the underlying ethical ideal: medical decisions should be made in a way that respects the patient and is aligned with his or her preferences in decision-making. While the move to autonomous decisionmaking was driven by the presumption that most people are rational, reasonable, and want to make these decisions for themselves, the evidence demonstrates that in fact if we are to respect patients' wishes in the decision-making process, we must generally share in the burdens of decision-making.

Another body of evidence that is poised to affect our concepts of decision-making is the work demonstrating substantial shortcomings in affective and regret forecasting (Loewenstein and Schkade 1999; Wilson and Gilbert 2003). This psychology research demonstrates that, in general, people's predictions of their future emotional states are highly unreliable. This work may have significant impact on medical decision-making based on a patient's predictions of his or her future emotional state. For example, if a man is in a car accident and suffers a high spinal cord injury, he may opt to forego life-prolonging medical interventions because he believes that his future quality of life with a spinal cord injury would be unacceptably low. In fact, data suggests that patients who live with spinal cord injury are generally as satisfied with their life as the general population (Abrantes-Pais Fde et al. 2007; Hicken et al. 2002; Putzke et al. 2002). This therefore calls into question the validity of the patient's decision to forego life-prolonging care. This work also has significant implications for advanced directives and many other forms of decision-making that are based on predictions of future perceived well-being because the right to make these decisions is predicated on the assumption that people can reasonably judge their future emotional states, which the empirical work refutes.

While ethical norms do not merely mirror empirical findings, understanding the data is critical if we are to develop realistic ethical constructs. For example, the finding that racial and ethnic disparities exist in no way undermines the ethical norm that people should be treated equally regardless of race/ethnicity. This is because the empirical findings do not call 
into question the ethical constructs. Alternatively, when empirical research demonstrates that the assumptions made in developing an ethical norm are incorrect (as in the case of decision-making, where empirical research demonstrates that a shared decision-making process is more consistent with the principle of respect for persons than is an autonomous decision-making model), we must rethink our ideals and construct new norms that are founded on underlying principles and build on valid data. Such work reminds the bioethics community that the principle of respect for autonomy was built upon the underlying principle of respect for persons (Beauchamp and Childress 2001, 64), and because most people prefer shared forms of decision-making, the norm of strict autonomous decisionmaking must be altered.

Indeed, it may be argued that all philosophical inquiry relies on empirical data, however the data used are generated solely by the experiences, perceptions, and ideas of the philosopher. Using empirical research, our ethical theories may be founded on more generalizable data, and therefore may be more applicable to a broader base. For example, some feminist ethicists have argued that the ethics of men, born from masculine experiences, constructs, and concepts lacks applicability to women, and therefore to society as a whole. Alison Jaggar (1992) argued that traditional ethics places greater emphasis on masculine traits (e.g., independence, autonomy, separation, mind, reason) and less on feminine traits (e.g., interdependence, community, emotion). Therefore, empirical inquiry can lay the foundation for a more universal ethic, one applicable to persons of different racial, ethnic, socioeconomic, and educational backgrounds.

\section{HIERARCHY OF THE CATEGORIES}

As noted previously, I believe that the four categories presented represent a hierarchy and not merely four separate but equal groups. To be clear, this is not to say that those in categories lower on the hierarchy are less important, less valuable, or of less merit than those in higher categories. Rather, the hierarchy is based on how such works logically build on one another. There are certainly instances when a step may be "skipped," or when work may take a reverse order, however in general I believe that there is a logical progression through the categories.

If we take the work on shared decision-making as an example of how such work may progress, we find that initially Lay of the Land studies demonstrated that many patients and their surrogates prefer to have their healthcare providers participate actively in healthcare decisions using a shared decision-making process (Azoulay et al. 2004; Heyland et al. 2003b; Johnson et al. 2000; Mazur et al. 2005; Salkeld et al. 2004; Shields et al. 2004). Ideal versus Reality studies then demonstrated that patients and families whose goals of care are determined using a shared decision-making process are generally more satisfied with the decision-making process and the care provided (Azoulay et al. 2005; Heyland et al. 2003a). Building on these findings, investigators then developed tools to teach shared decisionmaking to physicians, and Improving Care studies demonstrated increased patient satisfaction with the decision-making process when their providers receive training in shared decision-making (Bieber et al. 2006; 2008; Penticuff and Arheart 2005).

Due to the compelling evidence provided by the Lay of the Land and Ideal versus Reality studies, a meeting was held in 2003 by the Society of Critical Care Medicine and the American Thoracic Society (the leading professional societies for critical care providers in the United States) and the European Respiratory Society, the European Society of Intensive Care Medicine, and the Société de Réanimation de Langue Française (the leading professional societies for critical care providers in Europe). 
In a combined consensus statement citing previous data demonstrating shortcomings in both paternalistic and autonomy-driven decision-making models, these societies stated that there must be a change in our ethical norm away from autonomy-driven decision-making in the United States and away from paternalistic decision-making in Europe to a new paradigm of shared decision-making (Carlet et al. 2004; Thompson et al. 2004). This consensus statement is an example of a Changing Ethical Norms publication built on previous empirical work.

In the case of shared decision-making, the Improving Care studies were conducted after the Changing Ethical Norms publications. It would seem, however, that the more logical sequence would have been to: first, research what it is that patients want; second, determine whether the status quo meets our expectation; third, investigate whether changing the status quo would improve patient satisfaction with the decision-making process; and finally fourth, advocate for a change in our ethical norm. Although in the case of shared decision-making the order was altered, the logical hierarchy remains.

\section{CONCLUSIONS}

The ultimate goal of empirical inquiry is to improve care. While many tenets of bioethics have been derived from philosophical inquiry, empirical research is necessary as well to move forward in a well-reasoned and well-informed direction. Clearly, philosophical inquiry and empirical studies can work in concert, with each informing the other. As with all aspects of bioethics, the input of different experts with different training and techniques often yields the best results. The bioethics community should embrace both forms of inquiry as valid approaches to normative ethics.

\section{Acknowledgments}

This work was funded in part by grant number UL1 RR024146 from the National Center for Research Resources (NCRR), a component of the National Institutes of Health (NIH), and NIH Roadmap for Medical Research. The author also thanks Professor Robert A. Burt for his review and constructive criticism of an earlier version of this manuscript.

\section{References}

Abraham N, Wan F, Montagnet C, Wong YN, Armstrong K. Decrease in racial disparities in the staging evaluation for prostate cancer after publication of staging guidelines. Journal of Urology 2007;178(1):82-87. [PubMed: 17499294]

Abrantes-Pais Fde N, Friedman JK, Lovallo WR, Ross ED. Psychological or physiological: Why are tetraplegic patients content? Neurology 2007;69(3):261-267. [PubMed: 17460156]

Anderson CJ, Vogel LC, Willis KM, Betz RR. Stability of transition to adulthood among individuals with pediatric-onset spinal cord injuries. Journal of Spinal Cord Medicine 2006;29(1):46-56. [PubMed: 16572565]

Arnold, R.; Youngner, S. Core Competencies for Health Care Ethics Consultation. Oakbrook, IL: American Society for Bioethics and Humanities; 1998.

Azoulay E, Pochard F, Chevret S, et al. Half the family members of intensive care unit patients do not want to share in the decision-making process: A study in 78 French intensive care units. Critical Care Medicine 2004;32(9):1832-1838. [PubMed: 15343009]

Azoulay E, Pochard F, Kentish-Barnes N, et al. Risk of post-traumatic stress symptoms in family members of intensive care unit patients. American Journal of Respiratory Critical Care Medicine 2005;171(9):987-994.

Beach MC, Rosner M, Cooper LA, Duggan PS, Shatzer J. Can patient-centered attitudes reduce racial and ethnic disparities in care? Academic Medicine 2007;82(2):193-198. [PubMed: 17264700] 
Beauchamp, TL.; Childress, JF. Principles of Biomedical Ethics. 5. New York, NY: Oxford University Press; 2001.

Bieber C, Muller KG, Blumenstiel K, et al. Long-term effects of a shared decision-making intervention on physician-patient interaction and outcome in fibromyalgia. A qualitative and quantitative 1 year follow-up of a randomized controlled trial. Patient Education and Counseling 2006;63(3):357-366. [PubMed: 16872795]

Bieber C, Muller KG, Blumenstiel K, et al. A shared decision-making communication training program for physicians treating fibromyalgia patients: Effects of a randomized controlled trial. Journal of Psychosomatic Research 2008;64(1):13-20. [PubMed: 18157994]

Broome, ME. Intervention research in bioethics. In: Jacoby, L.; Siminoff, L., editors. Empirical Methods for Bioethics: A Primer. 1. Oxford, UK: Elsevier JAI Press; 2008. p. 203-218.

Campbell FA, Goldman BD, Boccia ML, Skinner M. The effect of format modifications and reading comprehension on recall of informed consent information by low-income parents: A comparison of print, video, and computer-based presentations. Patient Education and Counseling 2004;53(2): 205-216. [PubMed: 15140461]

Carlet, J.; Thijs, LG.; Antonelli, M., et al. Challenges in end-of-life care in the ICU. Intensive Care Medicine; Statement of the 5th International Consensus Conference in Critical Care: Brussels; Belgium. April 2003; 2004. p. 770-784.

Clinton, H.; Obama, B. National medical error disclosure and compensation act. 2005.

Criscione LG, Sugarman J, Sanders L, Pisetsky DS, St Clair EW. Informed consent in a clinical trial of a novel treatment for rheumatoid arthritis. Arthritis and Rheumatism 2003;49(3):361-367. [PubMed: 12794792]

Daaleman TP, Usher BM, Williams SW, Rawlings J, Hanson LC. An exploratory study of spiritual care at the end of life. Annals of Family Medicine 2008;6(5):406-411. [PubMed: 18779544]

DeKeyser Ganz F, Musgrave CF. Israeli critical care nurses' attitudes toward physician-assisted dying. Heart and Lung 2006;35(6):412-422. [PubMed: 17137943]

Dixon-Woods M, Ashcroft RE, Jackson CJ, et al. Beyond "misunderstanding": Written information and decisions about taking part in a genetic epidemiology study. Social Science and Medicine 2007;65(11):2212-2222. [PubMed: 17904716]

Duke G, Thompson S. Knowledge, attitudes and practices of nursing personnel regarding advance directives. International Journal of Palliative Nursing 2007;13(3):109-115. [PubMed: 17505403]

Faden, R.; Beauchamp, T. A History and Theory of Informed Consent. New York, NY: Oxford University Press; 1986.

Fein SP, Hilborne LH, Spiritus EM, et al. The many faces of error disclosure: A common set of elements and a definition. Journal of General Internal Medicine 2007;22(6):755-761. [PubMed: 17372787]

Fiscella K, Franks P, Gold MR, Clancy CM. Inequality in quality: Addressing socioeconomic, racial, and ethnic disparities in health care. Journal of the American Medical Association 2000;283(19): 2579-2584. [PubMed: 10815125]

Fox E, Myers S, Pearlman RA. Ethics consultation in United States hospitals: A national survey. American Journal of Bioethics 2007;7(2):13-25. [PubMed: 17366184]

Gallagher TH, Waterman AD, Garbutt JM, et al. US and Canadian physicians' attitudes and experiences regarding disclosing errors to patients. Archives of Internal Medicine 2006;166(15): 1605-1611. [PubMed: 16908793]

Heyland DK, Cook DJ, Rocker GM, et al. Decision-making in the ICU: Perspectives of the substitute decision-maker. Intensive Care Medicine 2003a;29(1):75-82. [PubMed: 12528026]

Heyland DK, Rocker GM, O'Callaghan CJ, Dodek PM, Cook DJ. Dying in the ICU: Perspectives of family members. Chest 2003b;124(1):392-397. [PubMed: 12853551]

Hicken BL, Putzke JD, Novack T, Sherer M, Richards JS. Life satisfaction following spinal cord and traumatic brain injury: A comparative study. Journal of Rehabilitation Research and Development 2002;39(3):359-65. [PubMed: 12173756]

Houle C, Harwood E, Watkins A, Baum KD. What women want from their physicians: A qualitative analysis. Journal of Women's Health 2007;16(4):543-550. 
Jacoby, L.; Siminoff, L. Empirical methods for bioethics: A primer. In: Baker, R.; Shelton, W., editors. Advances in Bioethics. 1. Oxford, UK: Elsevier JAI Press; 2008.

Jaggar, AM. Feminist ethics. In: Becker, L.; Becker, C., editors. Encyclopedia of Ethics. New York, NY: Garland Press; 1992. p. 363-364.

Joffe S, Cook EF, Cleary PD, Clark JW, Weeks JC. Quality of informed consent in cancer clinical trials: A cross-sectional survey. Lancet 2001;358(9295):1772-1777. [PubMed: 11734235]

Johnson MF, Lin M, Mangalik S, Murphy DJ, Kramer AM. Patients' perceptions of physicians' recommendations for comfort care differ by patient age and gender. Journal of General Internal Medicine 2000;15(4):248-255. [PubMed: 10760000]

Katz, J. The Silent World of Doctor and Patient. New York, NY: The Free Press; 1984.

Kon AA, Ackerson L, Lo B. Choices physicians would make if they were the parents of a child with hypoplastic left heart syndrome. American Journal of Cardiology 2003;91(12):1506-1509. [PubMed: 12804748]

Lee KJ, Dupree CY. Staff experiences with end-of-life care in the pediatric intensive care unit. Journal of Palliative Medicine 2008;11(7):986-990. [PubMed: 18788959]

Li S, Ng J. End-of-life care: Nurses' experiences in caring for dying patients with profound learning disabilities — a descriptive case study. Palliative Medicine 2008;28(8):949-955. [PubMed: 18799514]

Loewenstein, G.; Schkade, D. Wouldn't it be nice? Predicting future feelings. In: Kahneman, D.; Diener, E.; Schwarz, N., editors. Well-being: The Foundations of Hedonic Psychology. New York, NY: Russell Sage Foundation; 1999. p. 85-105.

Loewy EH. Ethical considerations in executing and implementing advance directives. Archives of Internal Medicine 1998;158(4):321-324. [PubMed: 9487228]

Luk LA, Ng WI, Ko KK, Ung VH. Nursing management of medication errors. Nursing Ethics 2008;15(1):28-39. [PubMed: 18096579]

Mazur DJ, Hickam DH, Mazur MD, Mazur MD. The role of doctor's opinion in shared decision making: What does shared decision making really mean when considering invasive medical procedures? Health Expect 2005;8(2):97-102. [PubMed: 15860050]

McGee G, Caplan AL, Spanogle JP, Asch DA. A national study of ethics committees. American Journal of Bioethics 2001;1(4):60-64. [PubMed: 11954647]

Mittal D, Palmer BW, Dunn LB, et al. Comparison of two enhanced consent procedures for patients with mild Alzheimer disease or mild cognitive impairment. American Journal of Geriatric Psychiatry 2007;15(2):163-167. [PubMed: 17272737]

Penticuff JH, Arheart KL. Effectiveness of an intervention to improve parent-professional collaboration in neonatal intensive care. Journal of Perinatal and Neonatal Nursing 2005;19(2): 187-202. [PubMed: 15923969]

Pilcher ES, Charles LT, Lancaster CJ. Development and assessment of a cultural competency curriculum. Journal of Dental Education 2008;72(9):1020-1028. [PubMed: 18768444]

Putzke JD, Richards JS, Hicken BL, DeVivo MJ. Predictors of life satisfaction: A spinal cord injury cohort study. Archives of Physical Medicine and Rehabilitation 2002;83(4):555-561. [PubMed: 11932861]

Rurup ML, Onwuteaka-Philipsen BD, Pasman HR, Ribbe MW, van der Wal G. Attitudes of physicians, nurses and relatives towards end-of-life decisions concerning nursing home patients with dementia. Patient Education and Counseling 2006;61(3):372-380. [PubMed: 15975757]

Salkeld G, Solomon M, Short L, Butow PN. A matter of trust — patient's views on decision-making in colorectal cancer. Health Expect 2004;7(2):104-114. [PubMed: 15117385]

Satcher D. The initiative to eliminate racial and ethnic health disparities is moving forward. Public Health Report 1999;114(3):283-287.

Schoen C, Osborn R, Huynh PT, et al. Taking the pulse of health care systems: Experiences of patients with health problems in six countries. Health Affairs (Millwood) 2005;(Suppl Web Exclusives):W5-509-25.

Sequist TD, Adams A, Zhang F, Ross-Degnan D, Ayanian JZ. Effect of quality improvement on racial disparities in diabetes care. Archives of Internal Medicine 2006;166(6):675-681. [PubMed: 16567608] 
Shields CG, Morrow GR, Griggs J, et al. Decision-making role preferences of patients receiving adjuvant cancer treatment: A University of Rochester Cancer Center community clinical oncology program. Supportive Cancer Therapy 2004;1(2):119-126. [PubMed: 18628188]

Sprung CL, Carmel S, Sjokvist P, et al. Attitudes of European physicians, nurses, patients, and families regarding end-of-life decisions: The ETHICATT study. Intensive Care Medicine 2007;33(1):104110. [PubMed: 17066284]

SUPPORT. A controlled trial to improve care for seriously ill hospitalized patients. The study to understand prognoses and preferences for outcomes and risks of treatments (SUPPORT). Journal of the American Medical Association 1995;274(20):1591-1598. [PubMed: 7474243]

Tait AR, Voepel-Lewis T, Malviya S, Philipson SJ. Improving the readability and processability of a pediatric informed consent document: Effects on parents' understanding. Archives of Pediatrics and Adolescent Medicine 2005;159(4):347-352. [PubMed: 15809387]

Thompson BT, Cox PN, Antonelli M, et al. Challenges in end-of-life care in the ICU: Statement of the 5th International Consensus Conference in Critical Care, Brussels, Belgium, April 2003 Executive summary. Critical Care Medicine 2004;32(8):1781-1784. [PubMed: 15286559]

Wilson, TD.; Gilbert, DT. Affective forecasting. In: Zanna, M., editor. Advances in Experimental Social Psychology. New York, NY: Academic Press; 2003. p. 345-407.

Yuval R, Halon DA, Merdler A, et al. Patient comprehension and reaction to participating in a doubleblind randomized clinical trial (ISIS-4) in acute myocardial infarction. Archives of Internal Medicine 2000;160(8):1142-1146. [PubMed: 10789607] 